\title{
Lipid Cell and Micropapillary Variants of Urothelial Carcinoma of the Ureter
}

\author{
Yu Miyama ${ }^{a}$ Teppei Morikawa $^{a} \quad$ Tohru Nakagawa $^{b}$ Yukio Homma \\ Masashi Fukayama ${ }^{a}$ \\ Departments of ${ }^{\mathrm{a}}$ Pathology and ${ }^{\mathrm{b}}$ Urology, Graduate School of Medicine, The University of \\ Tokyo, Tokyo, Japan
}

\section{Key Words}

HER2 - Histological variant · Immunohistochemistry · Pathological diagnosis · p53 - Ureteral cancer

\begin{abstract}
We report on a case of urothelial carcinoma (UC) with lipid cell and micropapillary variants in the ureter. A 64-year-old man presented with gross hematuria. Urinary cytology revealed the presence of atypical urothelial cells. Computed tomography and drip infusion/retrograde pyelography identified a mass-occupying lesion in the left mid-ureter, as well as left hydronephrosis. A clinical diagnosis of left ureteral cancer was given and the patient underwent left nephroureterectomy. Microscopically, the major component of the tumor was a conventional high-grade UC. In the invasive region, however, lipid cell and micropapillary variants of UC were also observed. Upon immunohistochemical analysis, all of the components were diffusely positive for cytokeratin 7 and p53. Intense membranous expression of human epidermal growth factor receptor 2 (HER2) was also observed in both the lipid cell and micropapillary variants of UC, whereas weak and incomplete staining was observed in most regions of the conventional UC. The pathological stage was PT3 N2. Multiple times, the patient experienced recurrence of the UC in the urinary bladder and urethra. Although the patient underwent total cystectomy and urethrectomy, 52 months following the initial surgery, signs of local recurrence developed, as well as multiple lymph node and bone metastases. The patient died 75 months following the initial surgery. To the best of our knowledge, this is the first reported case of a lipid cell variant of ureteral UC. The overexpression of HER2 may be associated with both the lipid cell and micropapillary variants of UC.
\end{abstract}


Miyama et al.: Lipid Cell and Micropapillary Variants of Urothelial Carcinoma of the Ureter

\section{Introduction}

Urothelial carcinomas (UCs) can present with diverse histological variants [1]. In rare instances, UCs feature neoplastic cells, distended by optically clear vacuoles that resemble lipoblasts. Under the current World Health Organization's classification system, this rare variant of urothelial tumor is referred to as the lipid cell variant [2]. Nearly all lipid cell variants of UC occur in the urinary bladder, and its pathogenesis is poorly understood [3-10]. Here, we report on a case of UC with lipid cell and micropapillary variants in the ureter. We also discuss the potential molecular mechanism(s) of these variants, based on immunohistochemical evaluations.

\section{Case Report}

A 64-year-old man presented with gross hematuria. Atypical urothelial cells were identified upon urinary cytology examination. Computed tomography and drip infusion/ retrograde pyelography revealed a mass-occupying lesion in the left ureter, at the level of the fourth and fifth lumbar vertebrae, as well as left hydronephrosis. Upon cystoscopic evaluation, no abnormal findings were detected in the urinary bladder. Following a clinical diagnosis of left ureteral cancer, the patient underwent left nephroureterectomy.

Gross examination of the resected specimen revealed a well-demarcated papillary lesion (measuring $35 \times 13 \mathrm{~mm}$ ) in the mid-ureter. Microscopically, the major component of the tumor was a conventional, high-grade UC (fig. 1a). In the invasive region, however, lipid cell and micropapillary variants of UC were also observed (fig. 1b, c). The lipid cell variant of UC is composed of neoplastic cells, which have aberrantly arranged nuclei and optically clear cytoplasmic vacuoles that stain negatively for periodic acid Schiff and Alcian blue. The micropapillary variant of UC, on the other hand, is characterized by a small papillary architecture, typically within the tissue retraction spaces, that is reminiscent of ovarian serous papillary carcinomas. Transition between the two UC variants was also observed. The tumor invaded beyond the muscularis propria and into the periureteric fat. Metastasis to the left common iliac lymph node was detected. Metastatic lesions were composed of conventional UC only. The pathological stage was pT3 N2. Surgical margins were shown to be free from tumor.

Immunohistochemical analysis was performed, as described previously [11]. All components exhibited diffuse positivity for cytokeratin 7 and p53 (fig. 1d), but stained negatively for the S-100 protein and vimentin. Intense membranous expression of human epidermal growth factor receptor 2 (HER2) was observed in both the lipid cell and micropapillary variants of UC, whereas weak and incomplete staining was observed in most regions of the conventional UC (fig. 1e, f).

After surgical intervention, three cycles of methotrexate, vincristine, doxorubicin, and cisplatin were administered as adjuvant chemotherapy. Ten months following surgery, recurrence of the tumor was detected in the urinary bladder, and transurethral resection was performed. The pathological diagnosis was a high-grade, noninvasive papillary UC, with no variants of UC detected. Despite receiving intravesical instillation therapy with bacillus Calmette-Guérin, the patient experienced recurrence of the UC, in the urinary bladder and urethra, multiple times. The patient underwent total cystectomy and urethrectomy 52 months after the initial surgery. A conventional high-grade invasive UC was identified in the urethra, with no residual carcinoma detected in the urinary bladder. Seven months after cystectomy, recurrent UC was detected in the penis, and radiation therapy was performed. 
Miyama et al.: Lipid Cell and Micropapillary Variants of Urothelial Carcinoma of the Ureter

Unfortunately, however, the tumor continued to grow and the patient developed multiple lymph node and bone metastases. The patient died 75 months after the initial surgery.

\section{Discussion}

We reported on a case of ureteral UC with lipid cell and micropapillary variants. The lipid cell variant of UC is extremely rare. Only 42 cases in the urinary bladder [3-10] and a single case in the renal pelvis [3] have been reported in the English literature thus far. To the best of our knowledge, this represents the first published report of a lipid cell variant of UC occurring in the ureter.

The pathogenesis of the lipid cell variant of UC is poorly understood. Diffuse p53 positivity of all histological components, upon immunohistochemical analysis, is suggestive of these components harboring a TP53 mutation, and sharing a common clonal origin. Lopez-Beltran et al. [5] have demonstrated that loss of heterozygosity patterns were the same for the lipid cell variant as they were for the conventional UC, further supporting this hypothesis.

Interestingly, HER2 was overexpressed in both lipid cell and micropapillary variants of UC compared to most regions of conventional UC, where HER2 expression was weak and incomplete. Micropapillary UC is characterized at the molecular level by frequent overexpression, gene amplification, and/or somatic mutation of HER2 [12-15]. De Giorgi et al. [9] have also reported on a case involving HER2 overexpression in the lipid cell variant of UC. Of particular note is a recent study which demonstrated that 3 out of 6 lipid cell variants of UCs were accompanied by a micropapillary variant [10], as also highlighted by this present case. This, therefore, suggests that there may be a close association between these two variants. It is possible that HER2 overexpression is associated with both the lipid cell and micropapillary variants of UC, and drugs targeting HER2 (e.g. trastuzumab) could be effective at treating these tumors in the future.

The lipid cell variant of UC is typically associated with advanced-stage disease and a poor prognostic outcome. Twenty-five (58\%) of 43 reported cases of the lipid cell variant of UC were deceased within 5 years of receiving a diagnosis [3-10]. A single published case of lipid cell variant UC, affecting the renal pelvis, also presented at an advanced stage (pT3). Despite surgical resection and treatment with chemotherapy, the patient died 8 months after being diagnosed [3]. In the case of our patient, he, too, had presented with advanced-stage (pT3 N2) disease, but survived for a relatively long period, i.e. 75 months after the initial surgery. Furthermore, none of the recurrent tumors was classified as a lipid cell variant of UC. Therefore, the prognostic significance of the lipid cell variant of UC is still unknown and remains to be determined.

In conclusion, we have reported a case of UC with lipid cell and micropapillary variants in the ureter. Overexpression of HER2 may be associated with both lipid cell and micropapillary variants of UC. Further research will need to be conducted in order to further elucidate the pathogenic/prognostic significance of the lipid cell variant of UC.

\section{Acknowledgements}

We are very grateful to Kei Sakuma for his excellent technical support. 
Miyama et al.: Lipid Cell and Micropapillary Variants of Urothelial Carcinoma of the Ureter

\section{Statement of Ethics}

The submitted documents represent original research that has not been published previously, either as a whole or in part, in any form. All authors have read and approved the manuscript.

\section{Disclosure Statement}

The authors have no conflicts of interest to declare.

\section{References}

1 Samaratunga H, Delahunt B: Recently described and unusual variants of urothelial carcinoma of the urinary bladder. Pathology 2012;44:407-418.

2 Lopez-Beltran A, Sauter G, Gasser T, Hartmann A, Schmitz-Drager BJ, Helpap B, Ayala AG, Tamboli P: Infiltrating urothelial carcinoma; in Eble JN, Sauter G, Epstein JI, Sesterhenn IA (eds): World Health Organization Classification of Tumours: Pathology and Genetics of Tumours of the Urinary System and Male Genital Organs. Lyon, IARC Press, 2004, pp 93-109.

-3 Leroy X, Gonzalez S, Zini L, Aubert S: Lipoid-cell variant of urothelial carcinoma: a clinicopathologic and immunohistochemical study of five cases. Am J Surg Pathol 2007;31:770-773.

-4 Kojima Y, Takasawa A, Murata M, Akagashi K, Inoue T, Hara M, Tokunaga Y, Minase T, Hasegawa T, Sawada $\mathrm{N}$ : A case of urothelial carcinoma, lipid cell variant. Pathol Int 2013;63:183-187.

5 Lopez-Beltran A, Amin MB, Oliveira PS, Montironi R, Algaba F, McKenney JK, de Torres I, Mazerolles C, Wang $\mathrm{M}$, Cheng L: Urothelial carcinoma of the bladder, lipid cell variant: clinicopathologic findings and LOH analysis. Am J Surg Pathol 2010;34:371-376.

-6 Soylu A, Aydin NE, Yilmaz U, Kutlu R, Günes A: Urothelial carcinoma featuring lipid cell and plasmacytoid morphology with poor prognostic outcome. Urology 2005;65:797.

7 McPherson VA, Ott M, Tweedie EJ, Izawa JI: Case report and review of the literature: rectal linitis plastica secondary to the lipoid cell variant of transitional cell carcinoma of the urinary bladder. Can Urol Assoc J 2012;6:431-434.

8 Shimada K, Nakamura M, Konishi N: A case of urothelial carcinoma with triple variants featuring nested, plasmacytoid, and lipoid cell morphology. Diagn Cytopathol 2009;37:272-276.

-9 De Giorgi G, Pizzolitto S, Sacco C, Kocjancic E, Frea B, Falconieri G: Lipoid-cell variant of urothelial carcinoma: report of a new case of the urinary bladder. Arch Ital Urol Androl 2007;79:173-175.

10 Behzatoğlu K: Urothelial carcinoma with shadow cell, lipid cell and sebaceous (skin adnexal) differentiation: clinicopathological and immunohistochemical study of 10 cases. Ann Diagn Pathol 2015;19:314-319.

11 Ichimura T, Morikawa T, Kawai T, Nakagawa T, Matsushita H, Kakimi K, Kume H, Ishikawa S, Homma Y, Fukayama M: Prognostic significance of CD204-positive macrophages in upper urinary tract cancer. Ann Surg Oncol 2014;21:2105-2112.

$\checkmark 12$ Ching CB, Amin MB, Tubbs RR, Elson P, Platt E, Dreicer R, Fergany A, Hansel DE: HER2 gene amplification occurs frequently in the micropapillary variant of urothelial carcinoma: analysis by dual-color in situ hybridization. Mod Pathol 2011;24:1111-1119.

-13 Ross JS, Wang K, Gay LM, Al-Rohil RN, Nazeer T, Sheehan CE, Jennings TA, Otto GA, Donahue A, He J, Palmer G, Ali S, Nahas M, Young G, Labrecque E, Frampton G, Erlich R, Curran JA, Brennan K, Downing SR, Yelensky R, Lipson D, Hawryluk M, Miller VA, Stephens PJ: A high frequency of activating extracellular domain ERBB2 (HER2) mutation in micropapillary urothelial carcinoma. Clin Cancer Res 2014;20:68-75.

14 Makise N, Morikawa T, Takeshima Y, Fujimura T, Homma Y, Fukayama M: Urinary bladder urothelial carcinoma with concurrent plasmacytoid and micropapillary differentiations: a report of two cases with an emphasis on serum carbohydrate antigen 19-9. Pathol Int 2015;65:495-500.

15 Li J, Jackson CL, Yang D, Noble L, Wheeler M, MacKenzie D, Adegun T, Amin A: Comparison of tyrosine kinase receptors HER2, EGFR, and VEGFR expression in micropapillary urothelial carcinoma with invasive urothelial carcinoma. Target Oncol 2015;10:355-363. 


\section{Case Reports in Oncology}

\begin{tabular}{l|l}
\hline Case Rep Oncol 2015;8:515-519 \\
\hline DOI: 10.1159/000442149 & $\begin{array}{l}\text { ○ 2015 The Author(s). Published by S. Karger AG, Basel } \\
\text { www.karger.com/cro }\end{array}$ \\
\hline
\end{tabular}

Miyama et al.: Lipid Cell and Micropapillary Variants of Urothelial Carcinoma of the Ureter
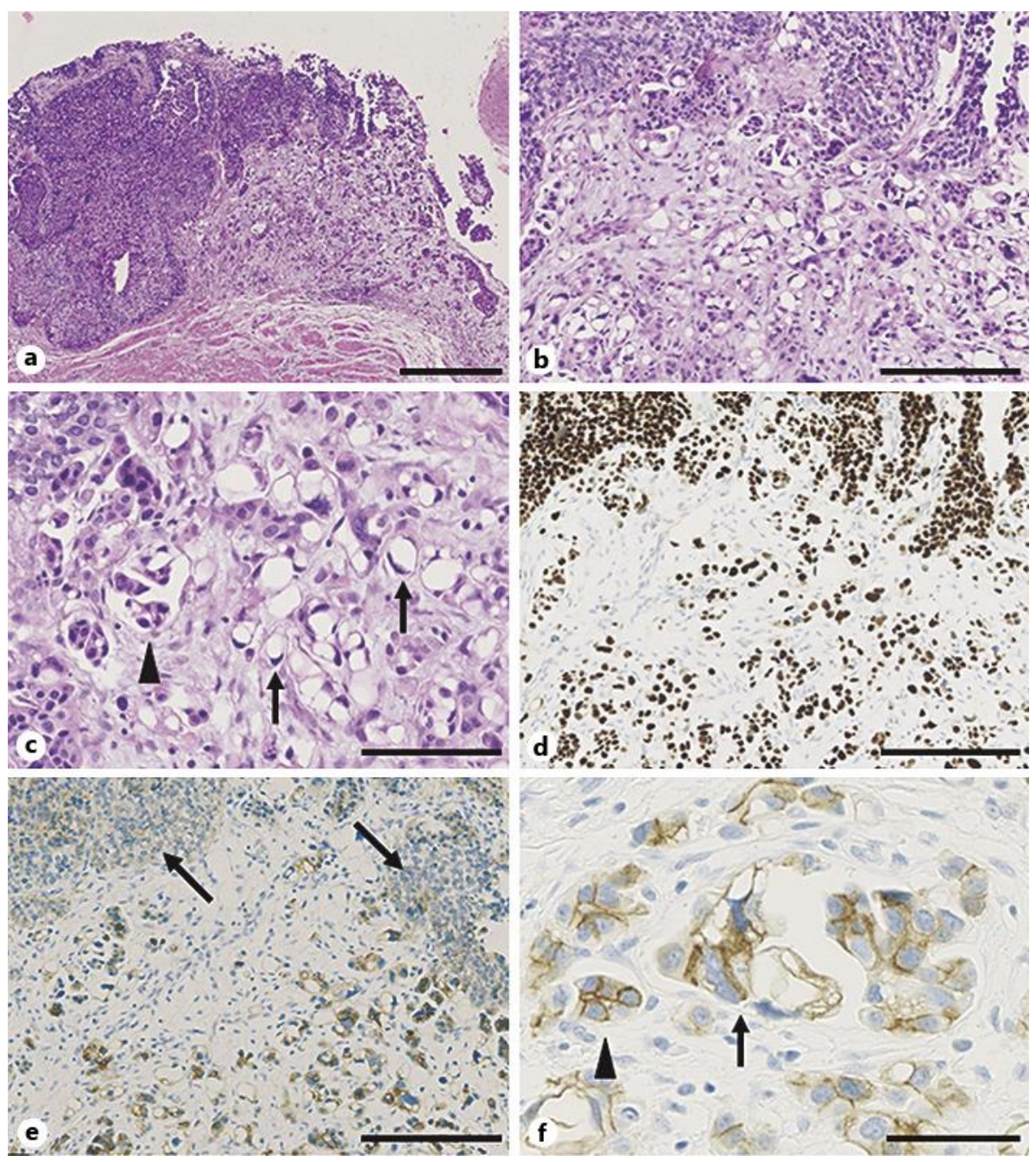

Fig. 1. Microscopic findings of the ureteral tumor. a Low-power view of the lesion. The tumor is composed of a conventional UC (left) with lipid cell and micropapillary variants (right). Hematoxylin and eosin (HE) staining. Bar, $500 \mu \mathrm{m}$. b Middle-power view of the lesion. HE staining. Bar, $200 \mu \mathrm{m}$. c High-power view of the lipid cell (arrows) and micropapillary (arrowhead) variants. HE staining. Bar, $100 \mu \mathrm{m}$. d Immunostaining for p53 at the same location as depicted in b. All tumor components stained diffusely positive for p53. Bar, $200 \mu \mathrm{m}$. e Immunostaining for HER2. HER2 expression was weak in the conventional UC (arrows), but is overexpressed in the lipid cell and micropapillary variants. Bar, $200 \mu \mathrm{m}$. $\mathbf{f}$ High-power view of HER2 immunostaining in the lipid cell (arrow) and micropapillary (arrowhead) variants. Bar, $50 \mu \mathrm{m}$. 